\title{
ANALYSIS OF IED CHARGE EXPLOSION ON CARRIER ROAD SAFETY
}

\author{
Waclaw Borkowski \\ Military Technical University \\ Institute of Motor Vehicles and Transport \\ Gen. Sylwestra Kaliskiego Street 2, 00-908 Warsaw, Poland \\ tel.: +4822 6839276, fax: +48226837370 \\ e-mail:wborkowski@wat.edu.pl \\ Grzegorz Motrycz \\ Military Institute of Armoured and Vehicle Technology \\ Automotive Vehicle Laboratory \\ Okuniewska Street 1, 05-070 Warsaw, Poland \\ tel.: +4822 6811046, fax: +48226811073 \\ e-mail: grzegorz.motrycz@witpis.eu
}

\begin{abstract}
The present article describes the aspect of the impact of damages to the vehicle wheel-and-suspension system on the vehicle dynamics. The authors present the results of the tests conducted as a part of the Research and Development Project No. O R00 0083 12, concerning the "Research into behaviour of a military personnel carrier following the explosive damage to tyres in order to determine the vehicle driving potential and the aspect of ensuring safety to the crew". The purpose of the article is to illustrate the methods of testing special vehicles by way of discussion of KTO Rosomak example as well as to determine the impact of IED bomb detonation under the vehicle wheel on the response of the driver, to estimate the level of acceleration in the centre of the vehicle mass, and to determine the impact of damages on the crew safety.

The research works have resulted in development of many models for simulation of the hazards, which are generated by the explosions of IEDs. In most cases, such models have not been validated by means of experimental procedures. There are presented a few experimental studies using the vehicles, which consist in detonation of explosives under the vehicles or close to the vehicles.
\end{abstract}

Keywords: IED; KTO Rosomak; safety; stability; steerability

\section{Introduction}

The term „Improvised Explosive Device” (IED) means a homemade bomb incorporating destructive, lethal, and noxious pyrotechnic agents or incendiary chemicals. The bomb is designed to destroy, neutralise, harass, or distract the opposing force. IEDs may incorporate military explosives; usually, however, they are made of the elements of other origins [7].

Being not original, the idea to resort to the IEDs used to reappear time after time in successive armed conflicts as a primary weapon of the poor. The IEDs became widespread in the 1970s during the British-Irish conflicts when the rebels (terrorists) from IRA started preparing homemade explosives (unsophisticated bombs), built often of smuggled recycled explosive materials and soil fertilisers. Typically, firing mechanisms and detonating systems were composed of simple electronic elements.

So far, the research and development works conducted by the universities as well as researchindustrial consortia have focused on the issues, which are essential to this area. These are:

- advanced anti-ballistic and anti-mine protection technology,

- study into the impact of impact charge on the rate of damages to the vehicle and the crew. 
The research works have resulted in development of many models for simulation of the hazards, which are generated by the explosions of IEDs. In most cases, however, such models have not been validated by means of experimental procedures. There are few experimental studies using the vehicles (conducted by P. Rybak, Ph. Dr., Eng., concerning the T-54 Tank, and by the Polish Ministry of National Defence, concerning the KTO Rosomak wheeled personnel carrier), which consist in detonation of explosives under the vehicles or close to the vehicles; there are also R\&D works conducted by AMZ Sp. z o.o (concerning, among others, TUR and ŻUBR vehicle series).

To this point, no research team has undertaken any study on the driver's response and the lateral dynamics of the vehicle following the explosion of an IED under the wheel or whilst the vehicle is driving.

\section{Purpose of research}

As mentioned in the previous section, the aim of the research was to concentrate on the analysis of the impact of IED detonation on the behaviour of an armoured personnel carrier. Still before, many millions Polish Zlotys had been spent on the determination of the impact of IEDs on the crew safety. From among various studies we would like to draw attention to the analysis of the impact of the explosion shock wave on the structures of military wheeled vehicles, the analysis of damages to vehicles following the explosions of land mines and improvised explosive devices (IEDs), and the description of the mechanisms responsible for such damages, specifically the injuries to the crew; the said analyses are presented in paper [1]. On the other hand, paper [2] presents the results of the studies conducted by another research team and concerning light armours of the vehicles as well as polymer-based anti-explosion shields, which protect the vehicles from the effects of detonation of the explosives. The problem of the impact of vehicle profile on the pressure pulse value has been discussed by yet another team in paper [3], which presents the results of numerical studies. Designs of the vehicle bodies were analysed and optimised along with the analyses of the injuries to the crew or else, methods were developed how to protect successfully the design from the effects of explosions.

There are, however, no papers concerning the impact of the explosion itself on the driver's behaviour or on the dynamics of a moving vehicle.

Improvised explosive devices are usually placed following a specific schedule that is close to essential and busy roads or crossroads [8]. The explosion of an IED generates a shock wave, which propagates in any direction. Depending on the IED mass and design, combined impact of the shock wave and device fragments will produce a pulse load on the vehicle [1]. Shown in Fig. 1 is the moment of explosion of an IED, which was hidden inside the road structure. The explosion happened when the vehicle was driving in convoy; the camera was installed on the vehicle.

The energy of explosion of such IEDs is massive and involves the vehicle destruction, which is almost impossible to be described. Even a standard mine containing $8 \mathrm{~kg}$ TNT can hardly compare with an IED mine, which contains more than $120 \mathrm{~kg}$ of the explosive material. Nonetheless, although the losses produced by such huge explosives are tremendous, the damages are not proportional to the size of the bomb. The bigger the bomb, the bigger will be the dissipation of the explosive energy. Furthermore, not only will such big bombs produce damages, but also extensive destruction of the entire vehicle.

The damages produced by the explosion depend mostly on [9]:

- energy of explosion, i.e. size (mass) and structure of the mine,

- place of explosion (in terms of geometry),

- structure of the subbase (sand; asphalt; rock).

The purpose of the experiment described in the present paper was to analyse the impact of the IED explosion on the behaviour of an armoured personnel carrier. The experiment included the stages specified below: 

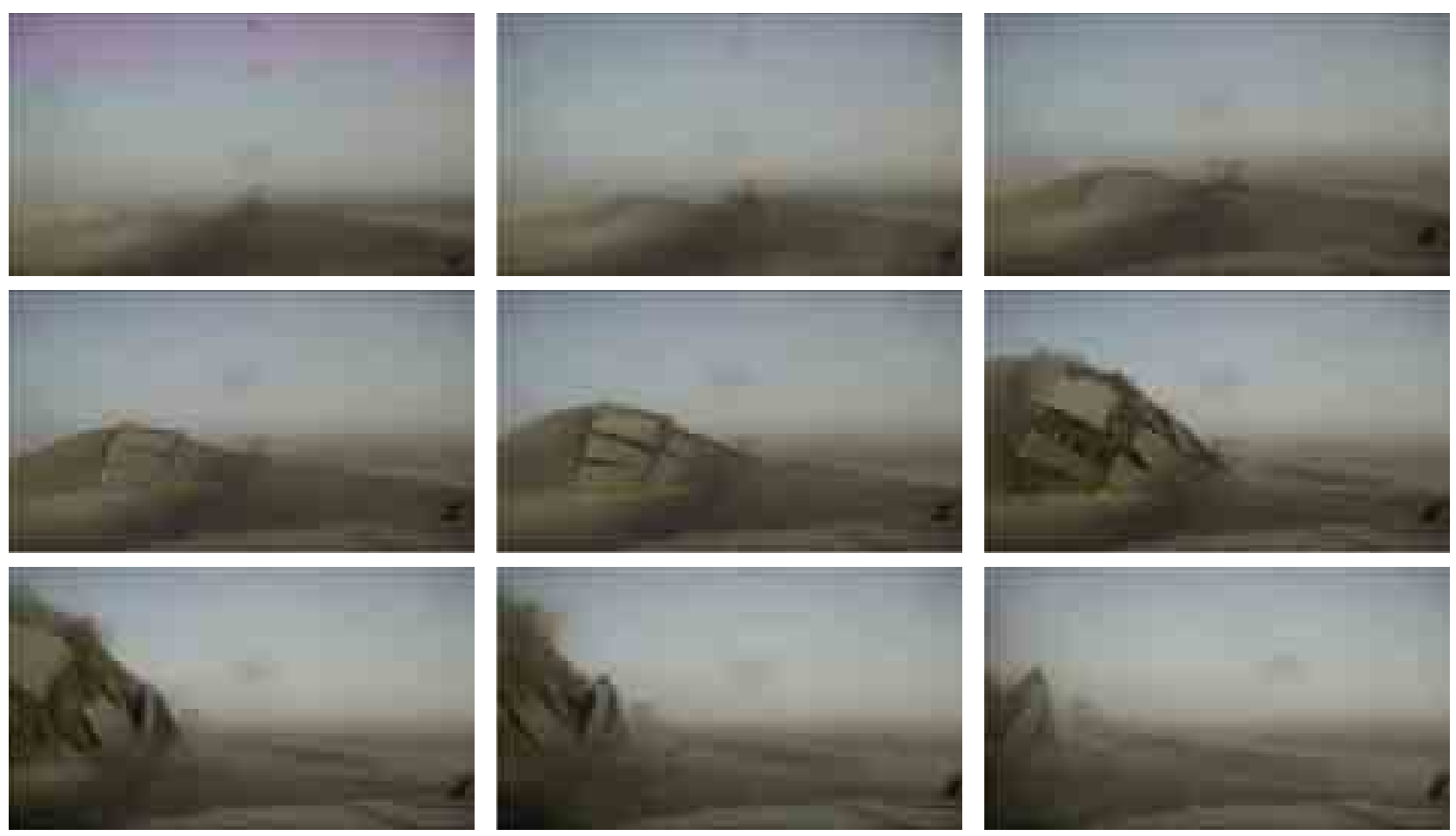

Fig. 1. Explosion of an IED hidden inside the road (Iraq) shown by the camera installed on the vehicle [source: www.yotube.com]

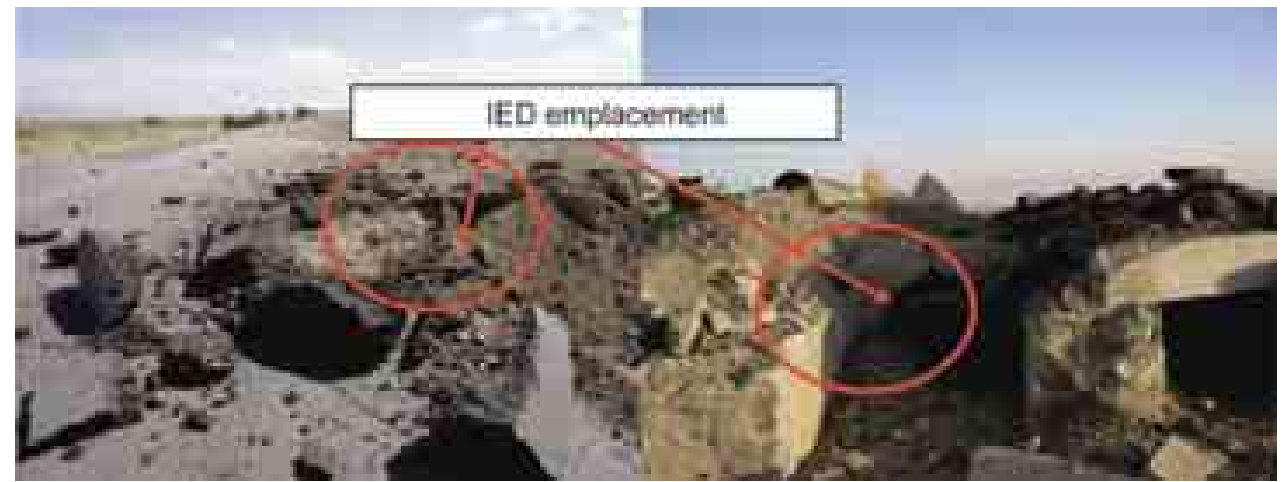

Fig. 2. Example of how the rebels (terrorists) used to locate the IEDs (photo: author's archives)

- installation of the measuring system on the object of tests (Fig. 4),

- production of the explosive (IED) and installation thereof on the measurement track (Fig. 5),

- test run.

\section{Test method}

The tests were conducted to a limited extent in the territory of Redzikowo, a closed military airfield, along a section of the road clad with concrete slabs. The purpose of the tests was to evaluate the level of dynamical loads acting on the vehicle body (internal equipment) and on the crew following the explosion of an IED under the vehicle wheel, as well as to asses the impact of the loads on the vehicle dynamics. Shown in Fig. 3 is the KTO Rosomak vehicle ready for the tests; shown in Fig. 4 is the place and method of fixing the sensors whereas Fig. 5 presents the test track.

Experimental data were collected using the Inertial and GPS Navigation System RT 3002 (measurement of angular velocities, linear acceleration values, and bodywork solid angles), and the MSW-2 S/N 103-4243 DATRON - Messtechnik double-parameter dynamometric steering gear (measurement of $\delta_{\mathrm{H}}$ and $\mathrm{M} \delta_{\mathrm{H}}$ ). 


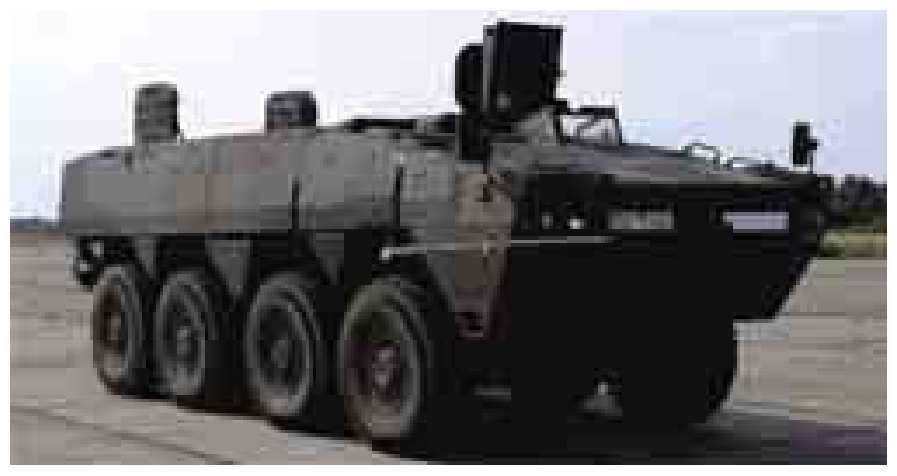

Fig. 3. KTO Rosomak ready for the tests (photo: G. Motrycz)
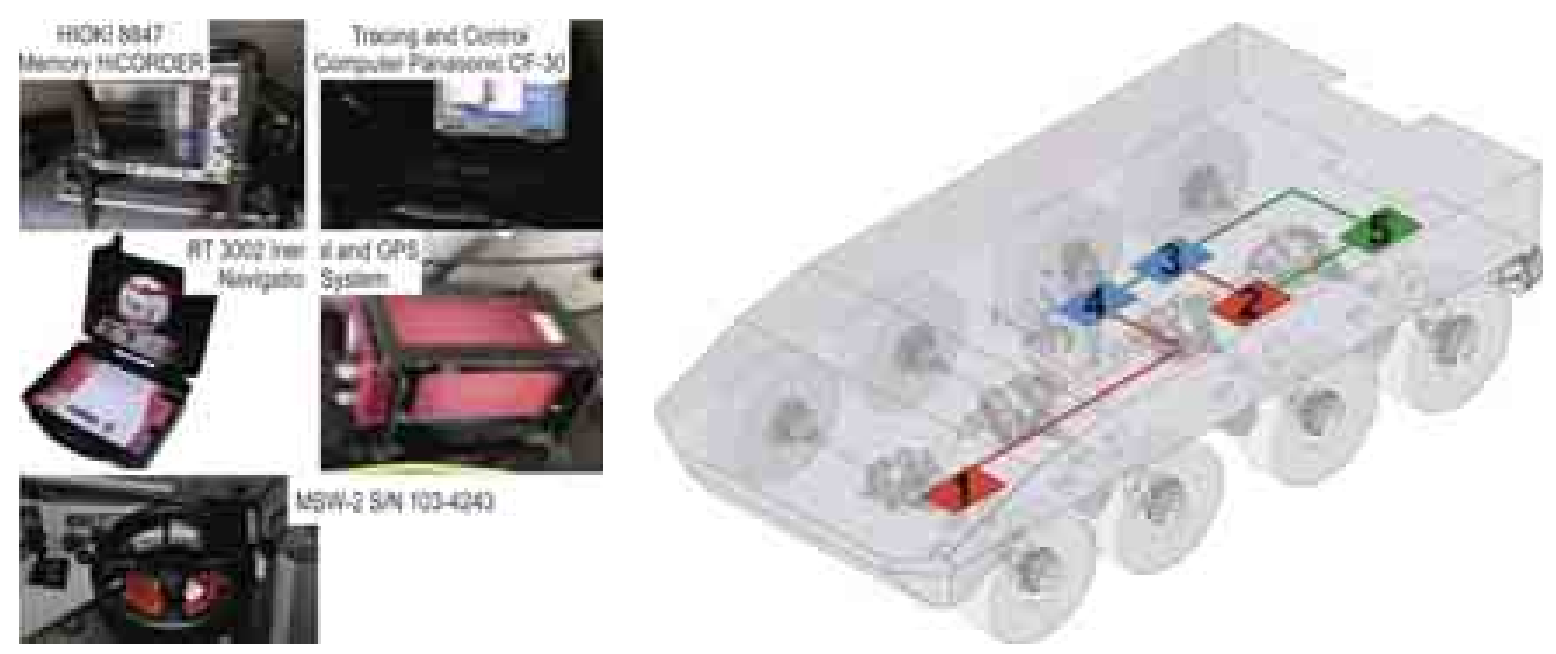

Fig. 4. Layout of the measurement system and view of the instruments used for the purpose of the experiment (photo and development: G. Motrycz) [6]

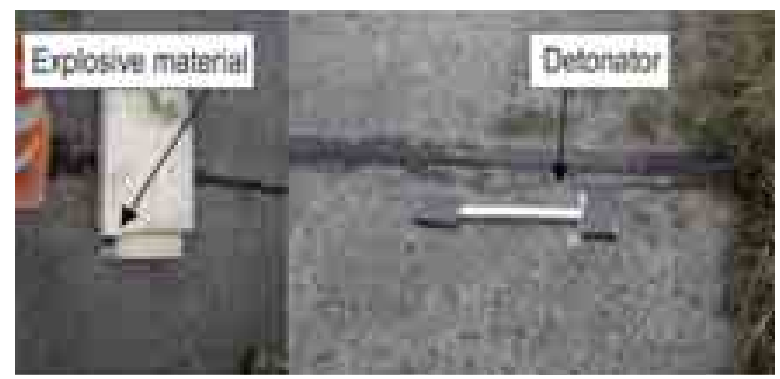

Fig. 5. Test track seen from KTO vehicle (photo: J. Ejsmont) [6]

The signals transmitted by the MSW-2 S/N 103-4243 (1), (2) sensing elements were recorded by means of the HIOKI 8847 Memory HiCORDER (4) transducer whereas the signals generated by the RT 3002 Inertial and GPS Navigation System were traced by the Panasonic CF-30 laptop (3). Power supply to the measurement system originated from an external source of voltage $(12 \mathrm{~V}-120 \mathrm{Ah}$ battery). The parameters such as e.g.: longitudinal $\left(\mathrm{V}_{\mathrm{L}}\right)$ and transversal $\left(\mathrm{V}_{\mathrm{Q}}\right)$ components of velocity vectors, three components of the vehicle angular velocity vector, and three angles which determine the position of the bodywork solid were taken and recorded during the measurement procedure along with three components of the vehicle linear acceleration vector at the point referred to the vehicle mass centre, steering gear angular displacement $\left(\delta_{\mathrm{H}}\right)$, and steering gear turning moment $\left(\mathrm{M} \delta_{\mathrm{H}}\right)$.

During the experiment, the KTO driver moved the vehicle along a pre-determined test track (corridor staked out by the posts). The explosion occurred at the moment when the vehicle righthand wheel drove onto the IED (Fig. 5) and when the left-hand wheel on the Axle 1 produced a short-circuit. 


\section{Analysis of the results}

Shown in Fig. 6 is the instant when the vehicle drove onto a waiting IED (Fig. 5).

a)

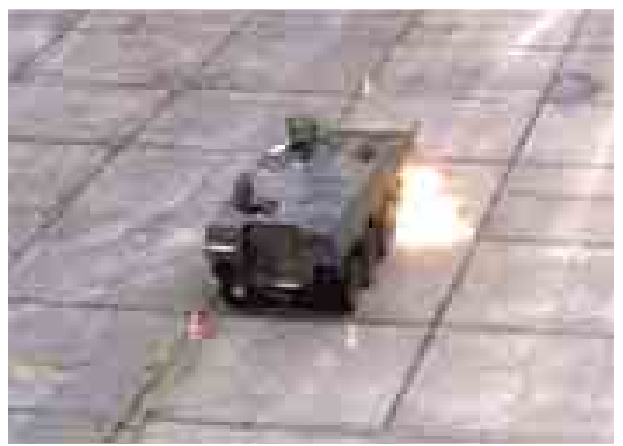

b)

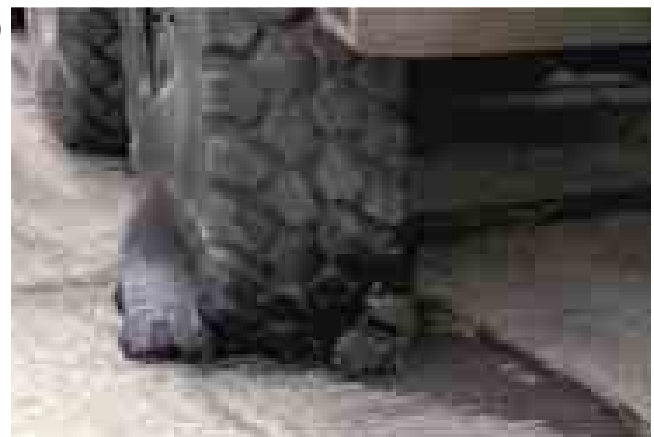

Fig. 6. KTO ROSOMAK during the tests (photo: G. Motrycz): moment of IED explosion under the wheel (a) and effects of IED explosion under the wheel (b)

Detonation of the IED under the wheel broke the tyre tread layer; additionally, the increased pressure inside the tyre broke the sidewall of the tyre (Fig. 7). The IED explosion period amounted to about 30 to 40 milliseconds. Within this period, the shock wave acted on the tyre and transferred the vibrations to the vehicle. In our particular case, the value of acceleration at the centre of vehicle mass increased by about $7 \mathrm{~g}$ along the $\mathrm{Z}$-axis and by about $3 \mathrm{~g}$ along the $\mathrm{Y}$-axis.

Once the tyre was broken, the shock wave damaged the Run Flat insert (Fig. 8).

a)

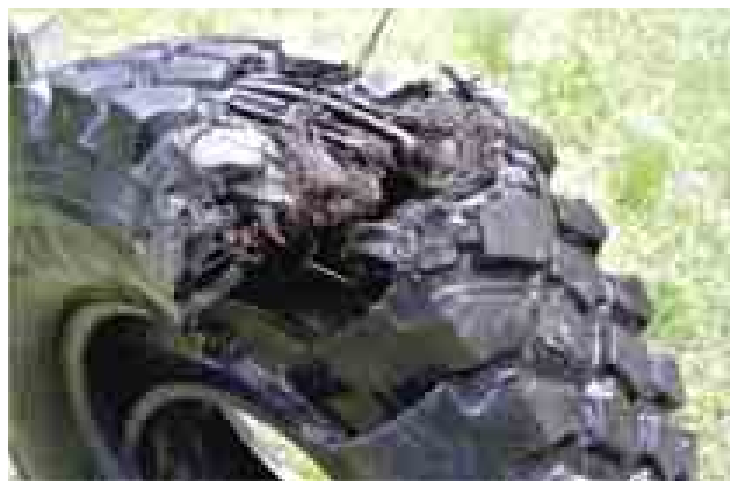

b)

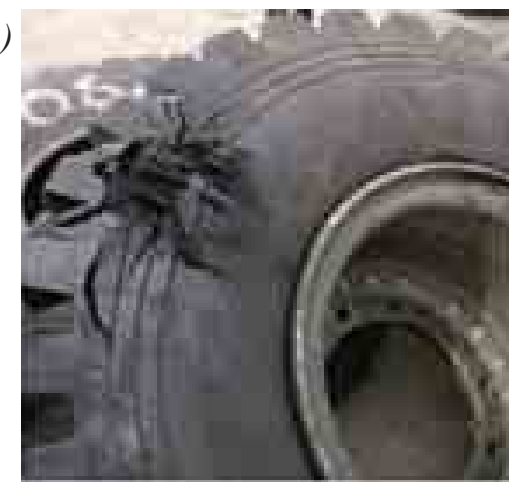

Fig. 7. Failures on the tyre following the crash into the IED: results of contact with IED (a) and results of increased pressure inside the tyre (b) (photo: G. Motrycz)

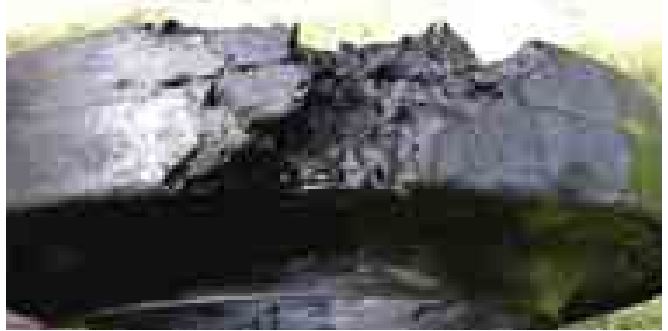

Fig. 8. Failures on the Run Flat insert following the crash into the IED (photo: G. Motrycz)

Even after the crash onto the IED the vehicle was able to drive and the damages to the tyre as shown in Fig. 7 (a) and (b) did not prevent evacuating the vehicle towards the base area. Longterm operations, however (driving with a damaged wheel) would lead to failures of the vehicle suspension components, such as e.g. equaliser springs. An example of long-term driving on a flat tyre is shown in Fig. 9. 


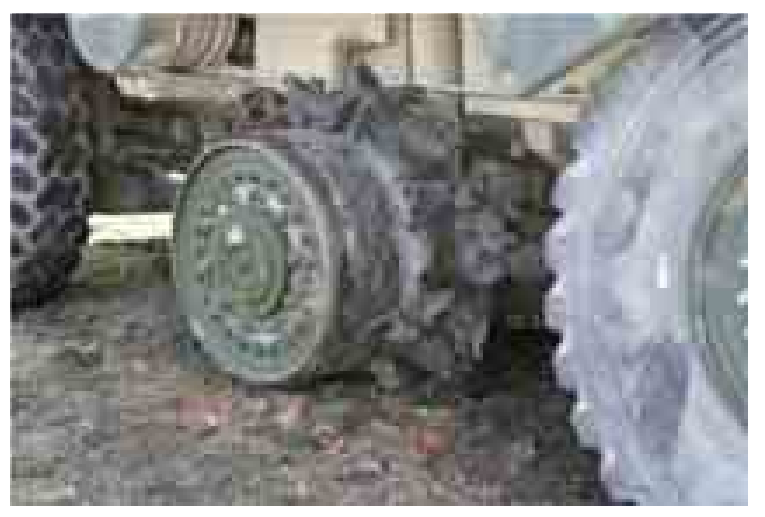

Fig. 9. Example damages to the KTO Rosomak vehicle wheel following long-term driving (photo: J. Piekarski/G. Motrycz)

If a bigger bomb was detonated or if the bomb was displaced with regard to the wheel position, the shock wave would reflect from the bottom body elements, affect the elements of the vehicle systems, and bring about damages. Occasionally, the energy would be high enough to throw the vehicle wheels sideways (the mass of a complete wheel amounting to about $225 \mathrm{~kg}$ ) (Fig. 10).
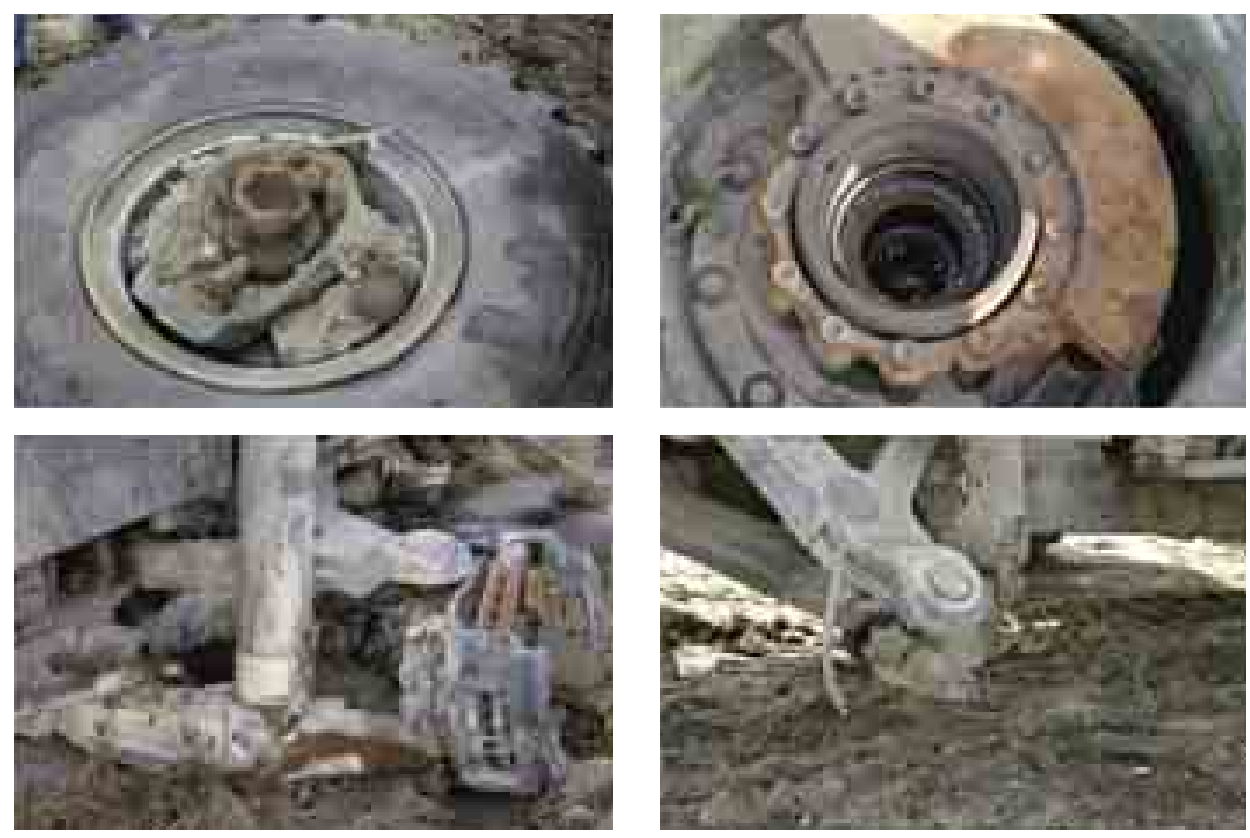

Fig. 10. Example of the impact of a reflected wave on the elements of the KTO Rosomak vehicle power transmission and suspension systems (photo: G. Motrycz).

The response of the vehicle to the pulse produced by the IED explosion was distinctive by the change in the vehicle mass centre drift angle and in the directional velocity (Fig. 12). The IED explosion under the vehicle wheel as shown in Fig. 11 took about $0.03-0.04$ second. Vertical acceleration component $\mathrm{a}_{\mathrm{z}}$ achieved its peak values (distributed at a uniform rate) within the ( -7 to $+7) \mathrm{g}$ interval.

When the IED exploded under the wheel, the steering wheel rotation angle was equal to $7^{\circ}$. At the same time, the driver instinctively clenched his fists on the steering wheel, which translated into the increase in the moment on the steering wheel by 2 [Nm]. After the explosion, the value of the moment on the steering wheel recovered its value at the level of $1[\mathrm{Nm}]$.

The moment on the steering wheel $\left(\mathrm{M} \delta_{\mathrm{H}}\right)$ was recorded during the experimental study. Prior to the run on the final test track, the driver made several pilot runs on various models of the test track. The values of the moment on the steering wheel were then lower than the values recorded in the case of the post-explosion run. 


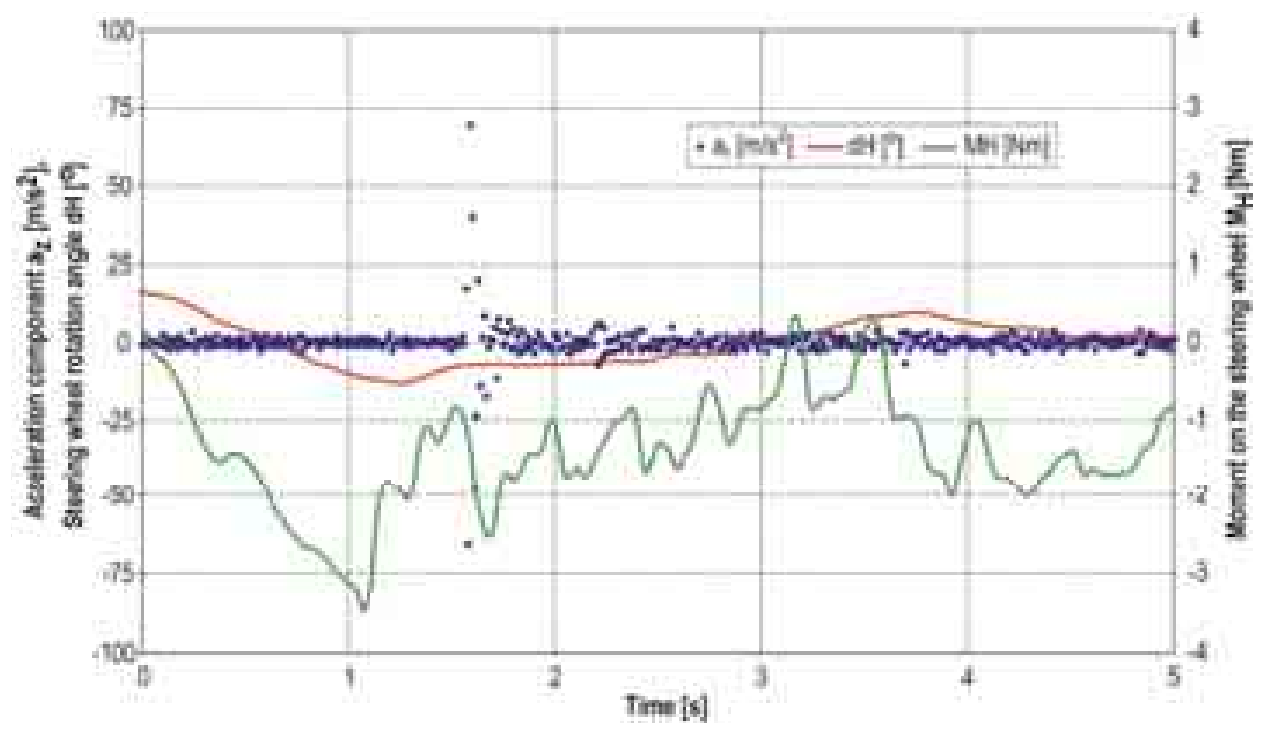

Fig. 11. Impact of IED explosion on the values of moments on the steering wheel

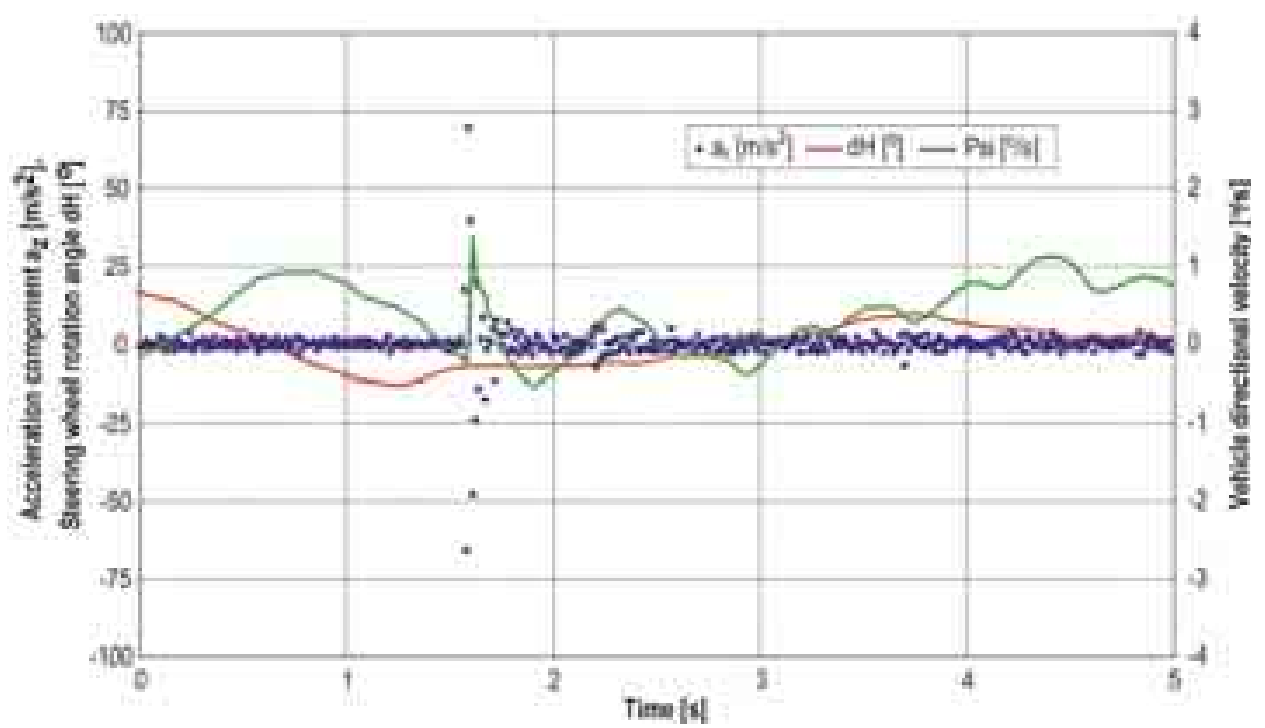

Fig. 12. Impact of IED explosion on the values of directional velocities and vehicle drift angle

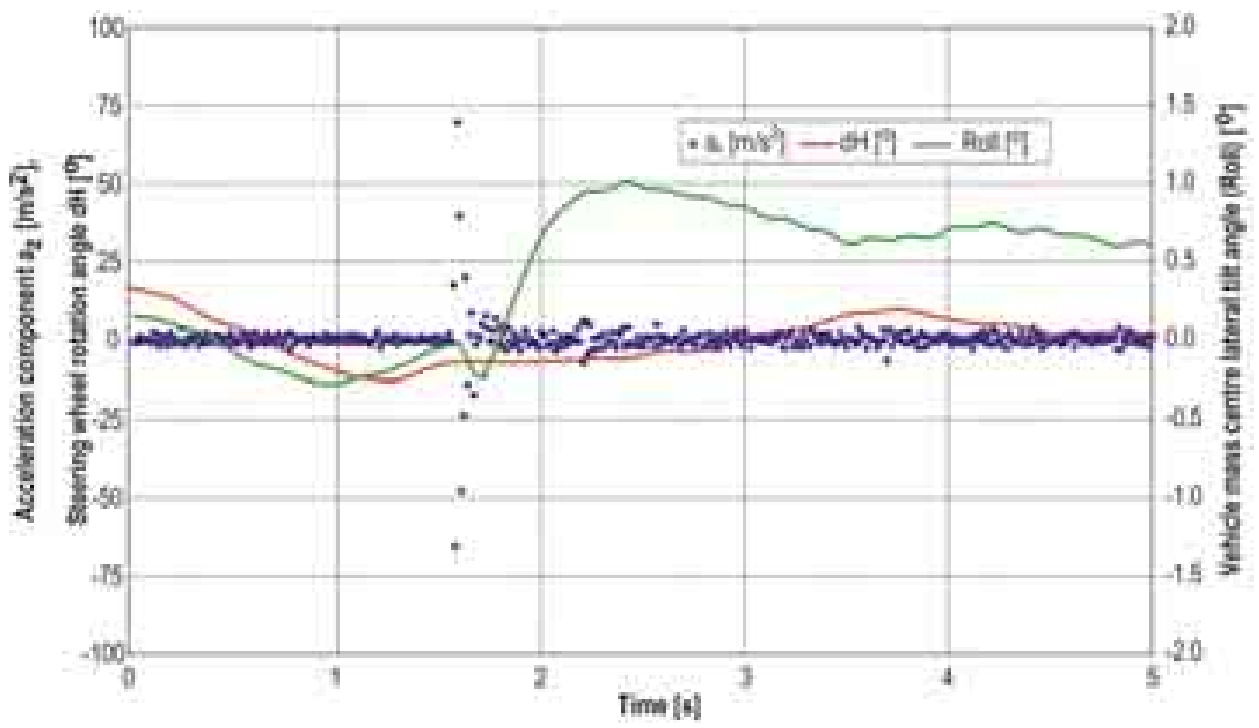

Fig. 13. Impact of IED explosion on the values of directional velocities and vehicle drift angle 
The above means that the human body will subconsciously respond to a hazard by nervous movements and reflexes, which consist in clenching, firm the fists in order to hold things. Should the driver be exposed to a long lasting condition of uncertainty, the response will be likely to look quite different and the attempts to evacuate the vehicle from the ambush will possibly often lead to tumbles.

The effect of explosion under the vehicle wheel reduced the value of the tilt angle down to $0.22^{\circ}$, and next increased it up to $2.43^{\circ}$ when the vehicle was driving straight ahead. At the moment of explosion, the initial value of the vehicle directional velocity amounted to $0.2[\% / \mathrm{s}]$ to increase from 0.25 up to $1.61[\% / \mathrm{s}]$.

\section{Summary}

The experimental study is a limited cognitional research work. In terms of functionality, the expectations for the vehicle have proved reasonable in the area of either vehicle lateral dynamics or safety criteria.

The preliminary analyses of the results of tests suggest the orientation of further experimental studies into the improvement in the design as well as the initial recommendations for the procedures for driver training.

\section{Acknowledgement}

Research work financed from the funds for sciences in 2010-2012 as the R\&D Project No. O R00 008312 and from the funds for sciences in 2011-2012 as the R\&D Project No. O N509 192340.

The experimental studies were ensured by the Polish Armed Force units, National Fire Brigade services, and JW 2305 unit soldiers. Technical side of the research object was ensured by the employees of Wojskowe Zakłady Mechaniczne S.A.

\section{References}

[1] Krzystała, E., Mężyk, A., Kciuk, S.: Analysis of the impact of explosion on special wheeled vehicles and their crews. Szybkobieżne Pojazdy Gąsienicowe (28), No. 2, 2011, pp. 99-110.

[2] Hasaj, W., Stępniak, W.: Selected types of new armours and shields protecting from the effects of detonation of blowing charges.

[3] Panowicz, R., Barnat, W., Niezgoda, T., Sybilski, K.: Numerical survey of the effect of a pressure pulse on selected types of vehicles and their crews. Mechanik, No. 5-6/2011, pp. 532-534.

[4] Borkowski, W., Rybak, P., Hryciów, Z.: Combat vehicle in stabilisation assignments. Journal of KONES Powertrain and Transport, Vol. 13, No. 1, pp. 73-81.

[5] Panowicz, R., Barnat, W., Niezgoda, T.: Numerical survey of the effect of a pressure pulse on selected types of vehicles and their crews. Mechanik, No. 5-6/2011, pp. 532-534.

[6] Motrycz, G., Stryjek, P., Ejsmont, J., Sobieszczyk, S.: Influence of IED explosion on lateral dynamics of a vehicle. Paper presented at the VTI 2012 China Conference.

[7] AAP-6 Glossary of NATO Terms and Definitions. AAP-6 (2005), p. 371.

[8] Borkowski, W., Rybak, P., Hryciów, Z., Michałowski, B.: Research into the impact strength of special vehicle shell. Teka Komisji Motoryzacji 2008, Vol. 33-34, pp. 29-36.

[9] Kałwa, H.: Analysis of damages to KTO Rosomak following the explosion of IED charges. WITPiS 2011 Report (not published). 